\title{
Enclaves fortificados e segregação urbana: o caso de Jundiaí
}

\author{
Jefferson Oliveira Goulart \\ Doutor em Ciência Política (Universidade de São Paulo) \\ Professor na Universidade Estadual Paulista
} jgoulart@faac.unesp.br

Patrícia Pechini Bento Graduação em Arquitetura (Universidade Estadual Paulista) Arquiteta no Conselho de Defesa do Patrimônio Histórico, Arqueológico, Artístico e Turístico do Estado de São Paulo paty_pechini@hotmail.com

\begin{abstract}
Resumo $\mathrm{O}$ artigo examina a proliferação de condomínios fechados no município de Jundiaí (SP). Os estudos sobre este fenômeno retratam predominantemente as regiões metropolitanas, daí a relevância de pesquisas sobre cidades de médio porte a fim de identificar semelhanças e diferenças entre essas diferentes escalas urbanas. O objetivo principal foi investigar o fenômeno espacializado dos condomínios fechados como tendência de padrão habitacional, assim como seus impactos sociais, urbanísticos e ambientais, adotando-se como escopo cronológico o período que se inicia a partir da década de 1970 até o presente momento.
\end{abstract}

Palavras-chaves: enclaves fortificados; segregação urbana; Jundiaí.

$\mathrm{E}$ Ste artigo aborda a propagaÇão de condomínios fechados em Jundiaí (SP). Tal escolha se justifica pela relevância do tema como tendência contemporânea de expansão urbana e por sua inclinação segregadora. Estudos disponíveis sobre esse tema retratam predominantemente capitais e regiões metropolitanas, daí o valor de análises empíricas de cidades de médio porte a fim de identificar originalidades e/ou semelhanças. O fenômeno foi examinado de forma espacializada, tanto como tendência de padrão habitacional, quanto em seus impactos sociais, urbanísticos e ambientais. Para tanto, toma-se como ponto de partida a década de 1970 e segue-se até o presente período.

Metodologicamente, procedeu-se à caracterização da expansão urbana e à catalogação dos empreendimentos imobiliários residenciais que se enquadram na categoria de 'enclaves fortificados', assim como sua espacialização no tecido urbano. Depois, foi realizada pesquisa de campo qualitativa. Por fim, delimitou-se uma área - o 'recorte territorial', região oeste do município - para aprofundar o estudo (Figura 1).

Jundiaí situa-se na Região Administrativa de Campinas, tem população de 342.983 habitantes e área aproximada de $433 \mathrm{~km}^{2}$, e sua taxa de urbanização é de $93,96 \%$. O Índice de Desenvolvimento Humano é 0,857 - posição privilegiada que lhe atribui o $12^{\circ}$ lugar no ranking brasileiro $^{2}$. Além de estar localizado entre duas regiões metropolitanas,

1 Versão resumida de trabalho originalmente desenvolvido como pesquisa apoiada pela Fundação de Amparo à Pesquisa do Estado de São Paulo (Fapesp) com o título O Fenômeno dos Condomínios Fechados no Recente Processo de Urbanização de Jundiaí: um Estudo de Caso, concluída em 2008. 2 Para informações estatísticas mais detalhadas da cidade, consultar os sítios da Prefeitura do Município (<http://www.jundiai.sp.gov.br>), do Instituto Brasileiro de Geografia e Estatística (http://wnw. ibge.gov.br>) e da Fundação Sistema Estadual de Análise de Dados (<http://uww.seade.gov.br>). 


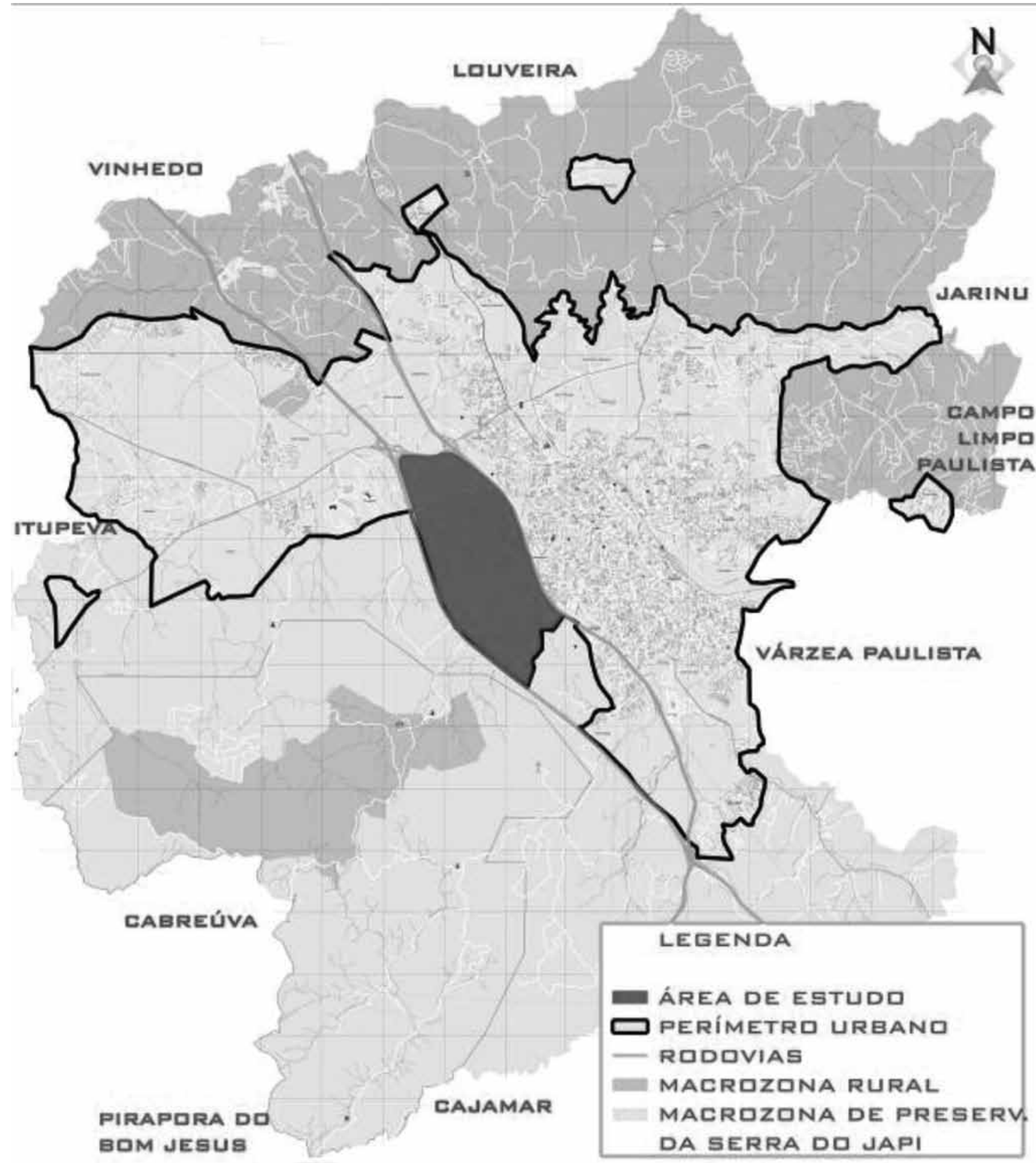

São Paulo e Campinas, o município é cortado pela vias Anhanguera e Bandeirantes, um dos principais e mais modernos eixos viários do país. Pela Lei Estadual n. 4.095/1984, as zonas urbana e rural foram declaradas Áreas de Proteção Ambiental, medida a partir da qual foram criadas quatro zonas ambientais. A partir da década de 1970, a cidade beneficia-se da descentralização industrial da Região Metropolitana de São Paulo, processo dirigido às áreas dinâmicas do interior paulista por meio do qual o governo estadual interveio, especialmente na melhoria da malha viária dos principais eixos. A essa ação atrativa, some-se a intervenção das administrações municipais no sentido de ampliar benefícios fiscais e tributários para as empresas do setor industrial (Cano, 1977; Negri, 1988).

Desde os anos 1980, há forte pressão da malha urbana sobre a Serra do Japi e expansão significativa sobre a zona rural, movimento protagonizado sobretudo pelas classes altas. As pressões do mercado imobiliário sobre a administração pública vêm se tornando 
frequentes, particularmente na elaboração do Plano Diretor, em 2004, quando tais interesses ficaram evidentes com a defesa da flexibilização das normas de uso e ocupação do solo nessas áreas ambientalmente frágeis, as quais demandam legislação rígida quanto à ocupação e fiscalização para inibir a disseminação de loteamentos irregulares. Apesar de o Plano Diretor definir o setor noroeste como vetor de expansão, foi permissivo na ocupação das regiões sudeste e norte. A Lei Complementar no 144/95 também exprime tolerância, ao admitir a regularização de loteamentos clandestinos ou irregulares. A expansão de condomínios fechados na cidade está relacionada às suas vantagens logísticas (proximidade da capital e de rodovias), à qualidade de vida oferecida e aos preços de imóveis e terrenos (estima-se que 15-20\% mais baixos que os similares em São Paulo).

\section{A lógica da segregação}

Historicamente, as cidades sempre apresentaram algum caráter polarizador por se associarem a classes e grupos que se diferenciam na apropriação do espaço urbano e do capital econômico, social, cultural e simbólico (D’Ottaviano, 2008). Barreiras visíveis ou imaginárias, físicas ou imateriais, são decisivas para organizar e dividir o espaço urbano. Na América Latina em geral e no Brasil, em particular, a segregação socioespacial é ainda mais expressiva em razão da forte concentração de renda.

Caldeira (2000) indica três formas de configuração urbana no Brasil do século XX, marcadas por diferentes modos de segregação. A primeira predominou até 1940: tinha malha compacta e aglomeração dos diferentes grupos sociais, segregados pelas moradias desiguais. A partir dos anos 1940, crescem os movimentos migratórios dirigidos aos centros urbanos e se acentua a polarização entre áreas ricas e pobres, tipificando assim a cidade industrial. As classes média e alta residiam no centro, amparadas por moderna infraestrutura, ao passo que as demais se deslocavam para loteamentos precários nas franjas do território urbano - na maioria, irregulares. Finalmente, a partir da década de 1980, surge uma terceira forma, fractal: o padrão segregacionista prevalece, mas de maneira espacialmente diferente da oposição centro x periferia que distingue os ciclos precedentes Apesar deste modelo, o novo padrão dos 'enclaves' caracteriza-se pela proximidade entre os grupos sociais, separados por barreiras físicas (muros e grades) e eficientes sistemas de controle e segurança que evitam a interação entre diferentes classes.

'Enclaves fortificados' representam um modo arbitrário de alteração de regras universais de convivência, diferenciação social e urbana que estimula atitudes e discursos acusativos relacionados à discriminação e à rejeição, dando lugar a processos de estigmatização de determinada categoria social (no caso, os pobres) que, na prática, assumem múltiplos formatos de evitação. Dessa forma, são organizadas relações sociais estruturadas na hierarquização de grupos considerados inferiores e potencialmente ameaçadores.

Nesse ambiente de distinção social - traduzido no cenário urbano sob várias contradições: opulência/miséria, solidez/vulnerabilidade, público/privado - se generalizam mecanismos de separação entre ricos e pobres. Tudo concorre para esvaziar os espaços públicos e inibir ou mesmo suprimir o convívio entre diferentes. A alteridade rareia, reforçando os mecanismos (sutis ou grosseiros) de evitação. Cenário desolador: a proliferação de condomínios fechados ocorre justamente quando a sociedade se esgarça, isto é, a 'demonização do outro' é necessária precisamente para justificar o recolhimento ao mundo privado e a homogeneização social defendida por muros, grades e segurança privada.

Enclaves fortificados "são propriedade privada para uso coletivo e enfatizam o valor do privado ao mesmo tempo em que desvalorizam o que é público e aberto na cidade" (Caldeira, 2000, p. 258). Enquadram-se neste grupo shopping centers, conjuntos de escritórios, além de espaços modificados para se integrarem como escolas, hospitais, parques temáticos etc. Cercados por muros ou grades, se notabilizam por uma 'arquitetura defensiva', voltada para o seu interior. São monitorados por modernos sistemas de segurança, alarmes, câmeras de circuito fechado, guardas de segurança muitas vezes armados. Seus moradores valorizam viver em ambientes socialmente homogêneos; evitam movimento, interações indesejadas, imprevisibilidade das ruas, ou seja, contrariam os ideais do urbanismo moderno - a cidade como um espaço aberto e democrático, no qual diferenças e pluralidade são aspectos positivos para a convivência.

A preferência por condomínios fechados está associada a diversos fatores. Roitman (2004) afirma que as causas relacionam-se entre si, dividindo-as em dois grupos: estruturais e relacionadas à ação social. As causas estruturais são determinadas pela estrutura social, política, legal e econômica, e as segundas expressam as motivações e intenções dos próprios atores sociais. No primeiro grupo, destacam-se o aumento da insegurança e o temor de delitos, aumento da distância social entre ricos e pobres, fracasso do Estado como provedor de políticas públicas, tendência à polarização social e à difusão dessa moda pelos gestores urbanos. A motivação predominante, corroborada no caso de Jundiaí, é o aumento dos índices de criminalidade (violência urbana) que produz sensação de medo e insegurança.

Em virtude da expansão do consumo de massa, atualmente os símbolos de distinção não são mais os que outrora denotavam status social, pois objetos do 
vestuário como gravatas ou ternos não são mais exclusivos das classes altas (Caldeira, 2000). Some-se o fato de o processo de democratização ter reconhecido os pobres como cidadãos, permitindo que frequentassem espaços anteriormente destinados às elites. A ocupação de certo espaço no território urbano determina status, enseja uma hierarquia social desejada para exaltar diferenças. Existe, assim, uma disputa em torno da cidade e de seus rumos, e a constituição de espaços segregados inclui ingredientes econômicos e políticos. Essa dinâmica assume feições de um ciclo vicioso à medida que o controle do Estado - a decisão sobre para onde são efetivamente direcionados os investimentos públicos privilegia os próprios grupos dominantes.

Nesse cenário, o mercado imobiliário é agressivo: como outros espaços urbanos não estão disponíveis pelo alto valor do solo, explora o aumento da criminalidade enfatizando as estratégias de segurança, e assim exalta e valoriza o 'fala do crime' - conversas, comentários, narrativas e debates que têm como assunto o medo, com base em múltiplas experiências de violência (Caldeira, 2000). Tais diálogos moldam as opiniões, ainda que de maneira estereotipada. A utilização de elementos associados à segurança (muros, cercas elétricas etc.), além de expressar o medo, a insegurança, suspeita e a necessidade de proteção, realça elementos de distinção social e certo paladar estético, a 'estética de segurança'.

Desse modo se enfraquece o sentido de comunidade, pois nos enclaves fortificados busca-se individualidade, daí a estigmatização do 'outro' e a desvalorização do que lhe é externo. Membros de espaços atomizados temem serem separados uns dos outros, fazendo com que os vínculos entre o grupo e o meio externo sejam frágeis e instáveis. Enclaves fortificados otimizam a exclusão e o desenraizamento territorial, o que só agrava a desintegração social. Nesse cenário, os espaços públicos são relegados pela elite e cedem lugar a espaços pseudopúblicos: condomínios, shoppin$g s$, centros de escritórios, acrópoles culturais. As ruas de pedestres transformaram-se em canais de tráfego rápido, as praças e parques, em abrigo para mendigos e indigentes (Miglioranza, 2005). Barcellos e Mammarella (2007) advertem que um dos impactos da implantação de enclaves fortificados é a transformação das áreas centrais em periféricas e centralização das áreas periféricas, uma vez que são implantados em formatos desconexos da malha urbana, o que normalmente induz a um tipo de expansão urbana que ultrapassa os limites propostos pelos órgãos de planejamento.

Em Jundiaí, a Lei n.416/2004 regulamenta a implantação de condomínios fechados: estes adquirem a denominação de 'vilas residenciais', conjuntos de residências unifamiliares, localizados na zona urbana com área máxima de $10.000 \mathrm{~m}^{2}$, constituídos de edificações isoladas ou agrupadas, com acesso comum à via pública. As edificações devem estar voltadas para as vias ou áreas internas, sem acesso independente para a via pública. A fração do terreno e a frente mínima do lote são determinadas pelo zoneamento, tendo como gabarito máximo dois pavimentos, excetuando-se a garagem. Loteamentos fechados são regulamentados pela mesma lei: devem garantir a continuidade da malha viária urbana, não podem conter áreas institucionais dentro de seu perímetro interno e os moradores precisam garantir a manutenção das áreas comuns. Se for de interesse comum ou da Prefeitura, podem voltar a adotar a forma aberta. O sistema viário interno será objeto de concessão do poder público, desde que os moradores constituam entidade regularmente instituída para esse fim.

O Plano Diretor de 2004 prevê a obrigatoriedade do Estudo de Impacto de Vizinhança (EIV) nesse tipo de empreendimento, pois, além de impactar o sistema viário, implica alterações ambientais, assim como em seu entorno e na comunidade dentro do escopo municipal. O EIV, contudo, ainda não foi regulamentado, de sorte que não é autoaplicável.

\section{Segurança e individualidade em uma comunidade de iguais}

Mesmo sem valor científico como amostra quantitativa, a aplicação de questionário a moradores de condomínios e loteamentos fechados traz informações valiosas: as respostas constituem fonte preciosa para compreensão do universo valorativo desse grupo social e de suas expectativas sobre esses conjuntos. A análise que se segue leva em conta tais resultados.

Morar em condomínios fechados tem como motivo decisivo a busca por segurança. Não por acaso, este constitui o principal elemento explorado pelo setor imobiliário, que assim criou uma "demanda convencida pelo medo", manipulada pela mídia e pela iniciativa privada (Ferreira, 2006): medo e insegurança justificam a demanda crescente por essas fortalezas precisamente pelo que representam como produto de consumo. A maioria, porém, reconhece certa vulnerabilidade e que a segurança desses empreendimentos não é inteiramente eficiente.

Além do refúgio contra a violência e a insegurança, dentre as motivações principais dos entrevistados também se inclui a qualidade de vida, na maioria das vezes relacionada à proximidade com a natureza através de áreas verdes localizadas no interior do condomínio - aspectos fartamente utilizados pela propaganda correspondente (Figura 2). Tal fator atua na percepção dos moradores porque estão inseridos onde há densa arborização. Ademais, alguns empreendimentos estão localizados em Áreas de Preservação Permanente, aspecto que faz com que seus moradores se sintam protegidos dos problemas urbanos. 
Figura 2 - Município de Jundiaí: exemplos de propaganda de condomínios fechados
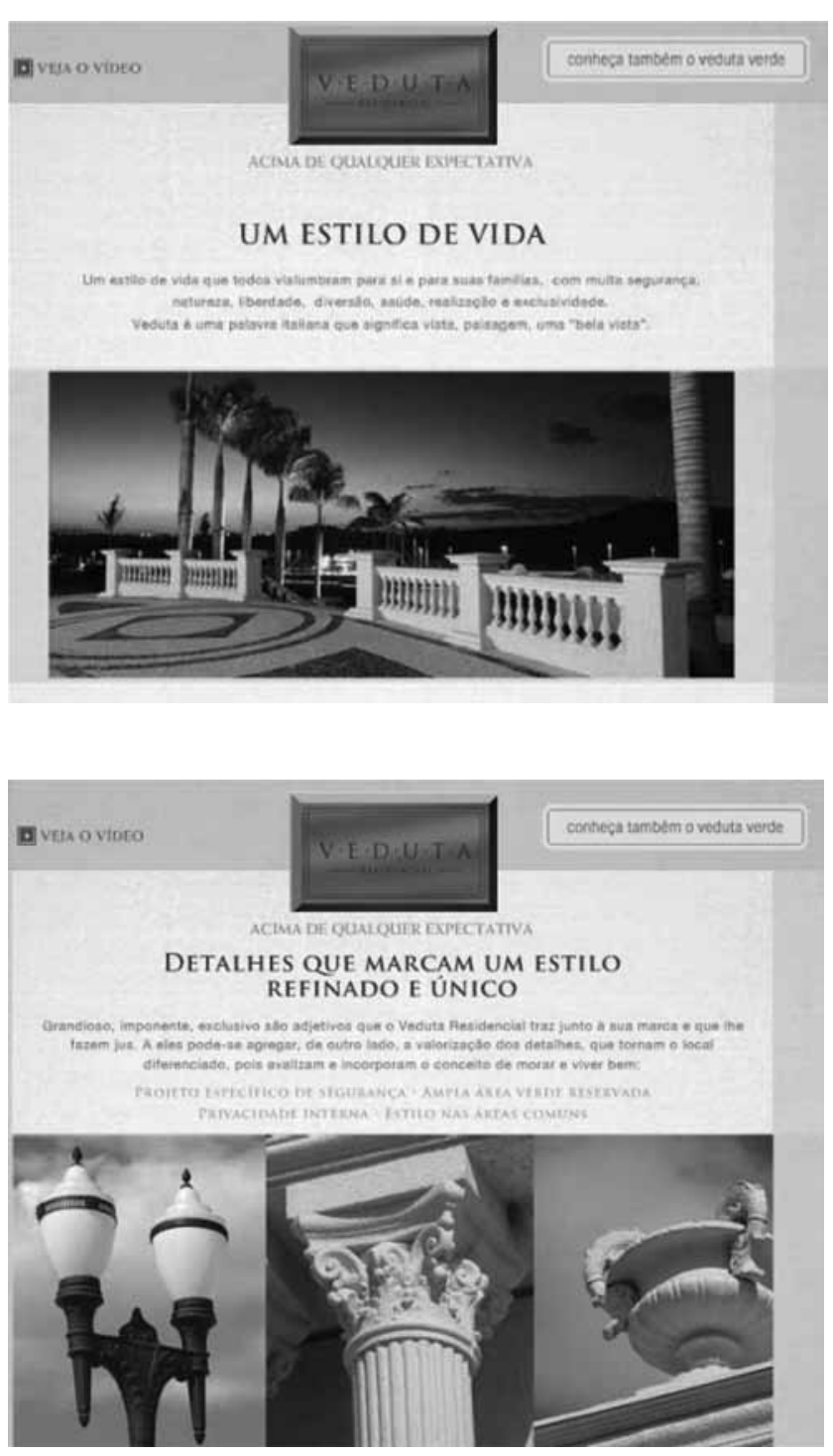

As guaritas são projetadas para mostrar imponência: há grandes arcos remetendo-os ao estilo neoclássico, e seus elementos principais - colunas, frontões, balaústres e estátuas - lhes conferem percepção de glamour e luxo onde somente pessoas 'distintas' e 'refinadas' poderiam residir. As guaritas ainda podem ser feitas de imponentes estruturas de aço que conferem mais rapidez de execução, leveza e modernidade ao espaço, visto que se trata de um material pouco difundido. Paredes externas geralmente são revestidas por pedra São Tomé (canjiquinha) ou pastilhas de vidro e cerâmica, podendo, ainda, apresentar texturas como, por exemplo, o graffiato. Nas guaritas, permanecem os seguranças, em geral armados, que fazem a seleção dos visitantes que acessam o condomínio: ficam em pequenas salas cercadas por portões e vidros cobertos com uma película de insul film, escuras o suficiente para não serem vistas. Salas estas equipadas com interfones e monitores que transmitem imagens das câmeras de segurança espalhadas pelo conjunto residencial.

O paisagismo dos espaços internos e dos muros incorpora plantas da moda, como palmeiras, bromélias,
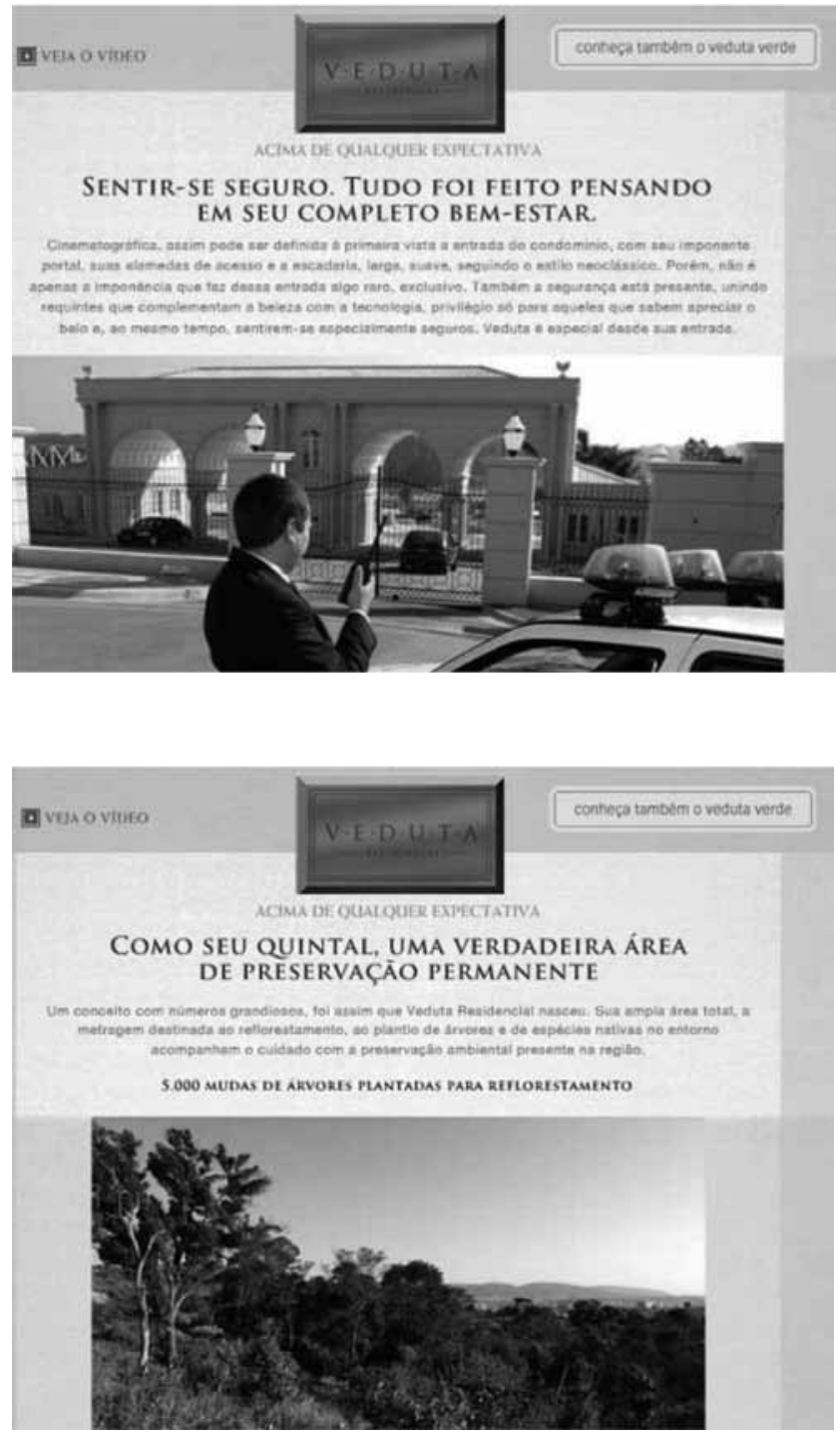

agapantos, pinheiros-de-Buda e icsórias. Tais artifícios criam um simulacro no interior da malha urbana, e assim simulam uma realidade perfeita que contrasta com a cidade - espaço de adversidades, imprevistos, violência, poluição e caos. Projetadas para empregar detalhes arquitetônicos sofisticados e sistemas de vigilância que promovem segurança a seus moradores, tais figuras atendem à demanda das classes abastadas. Janoschka e Borsdorf (2004) acrescentam que, além de homogeneidade social, tranquilidade e garantia de segurança, moradores dos enclaves não adquirem somente seu lote, mas o pacote completo, que se distingue pelo alto padrão de educação para suas crianças, networking etc.

A localização também é valorizada: muitos estão próximos às rodovias Anhanguera, Bandeirantes, Dom Gabriel Paulino Bueno Couto e à estrada municipal João Cereser, as quais facilitam o deslocamento dos seus moradores que trabalham ou estudam em cidades próximas como São Paulo, Campinas, Barueri etc. Muitos mantêm algum tipo de relação com cidades adjacentes devido ao fato de funcionarem como polo atrativo de 
mão de obra, além do número significativo de Instituições de Ensino Superior e ofertas de lazer e serviços. Desse modo, há um deslocamento pendular desses moradores que se articula com a hierarquia que modela o sistema viário do recorte territorial (Figura 3).

Regras de conduta interna são elaboradas por associações de moradores, fato que otimiza a governabilidade privada. A descrença na segurança pública é predominante, fazendo com que cultivem a ideia de que a ordem pública não poderia mesmo cumpri-la no interior do condomínio. Assim, "muitos moradores parecem tratar todo o complexo como casas particulares onde podem fazer o que lhes der na cabeça", de modo que assim "interpretam liberdade como uma ausência de regras e res- ponsabilidade em relação aos vizinhos" (Caldeira, 2000, p. 275). A transgressão de algumas normas públicas é admitida pela percepção de que regras internas seriam mais flexíveis e eventualmente mais justas, pois seriam mais adequadas àquela comunidade. Os diversos padrões habitacionais ratificam as diferenças sociais (Figura 4).

Já o contato com a população adjacente a esses conjuntos residenciais é praticamente inexistente, e ocorre somente quando seus moradores fazem uso do comércio local. Na maioria dos casos, este é pouco desenvolvido e se resume a estabelecimentos de serviços como padarias, mercados etc. Isto ocorre porque o comércio local não possui diversidade de produtos e marcas, fator valorizado por esses segmentos, que

Figura 3 - Município de Jundiaí: Hierarquia de Vias no Recorte Territorial

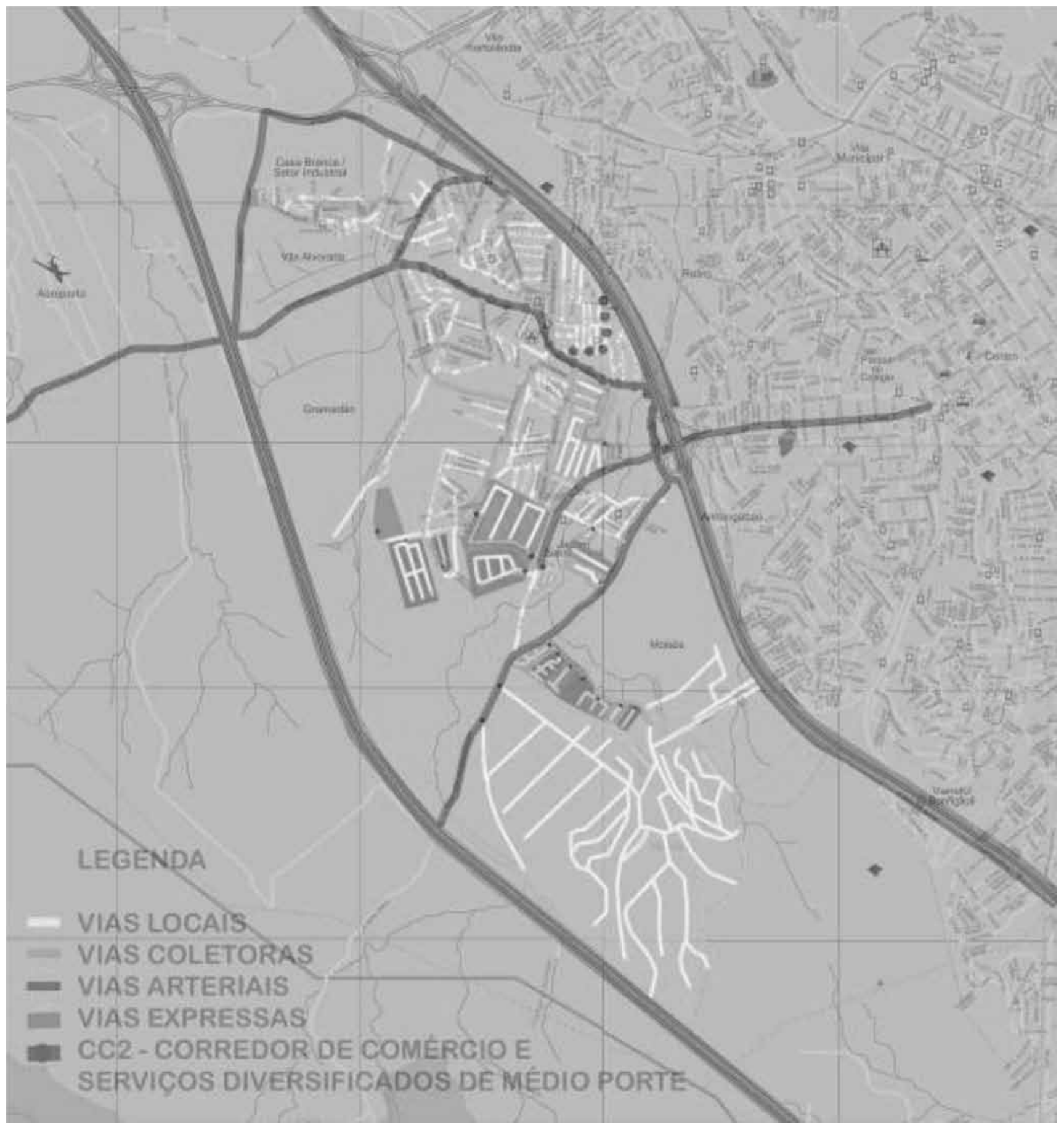




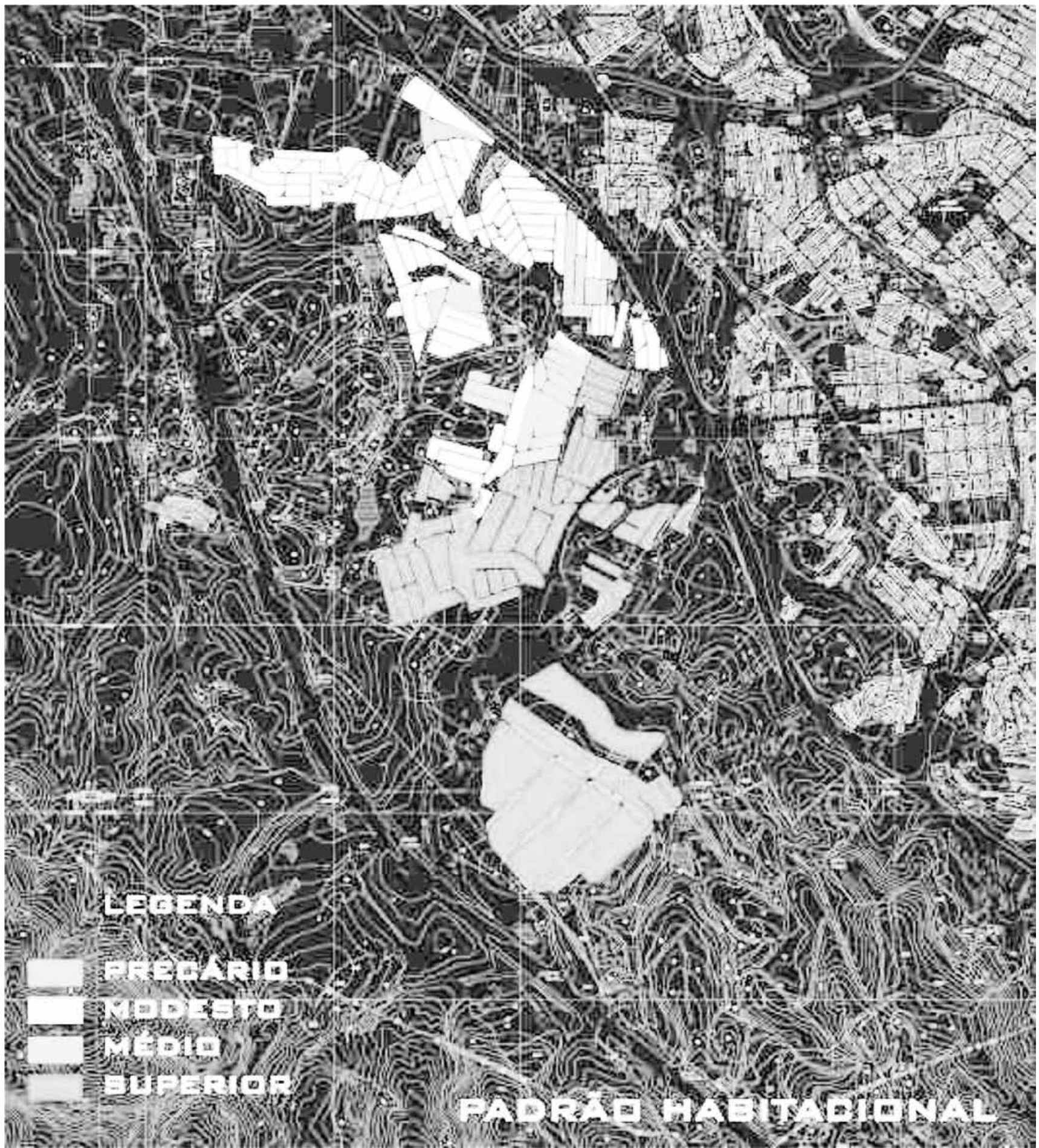

procuram bens de consumo mais sofisticados. Tal demanda é prontamente atendida pelos shoppings, que oferecem conforto (estacionamento, ar condicionado, praça de alimentação, atendimento personalizado etc.), evitando assim outros deslocamentos.

Moradores dos enclaves valorizam ambientes socialmente homogêneos, optam por não se mesclarem no mesmo território com pessoas de diferentes classes sociais e etnias, reduzindo os intercâmbios fora do simulacro ao mínimo indispensável. O conceito de comunidade está relacionado à ideia de pertencimento, e assim gera sentimentos de conforto e segurança ao mesmo tempo em que implica perda de individualidade. Tais fatores formam um cotidiano repleto de sentimentos como o provisório, o especulativo, incerteza, e assim a solidez é substituída pelo efêmero: a comunidade surge como "intencionalidade elaborada no cotidiano de precariedade e risco que a todos atinge" (Spinelli, 2006, p. 11).

Questionados sobre suas relações com os demais moradores do condomínio fechado, os entrevistados afirmaram, na maior parte dos casos, não manter contato com os vizinhos, estabelecendo apenas relações 
de cordialidade. A proximidade entre a vizinhança se mostra mais comum nas famílias que têm crianças. $\mathrm{O}$ fato de essas casas possuírem área de lazer contribui para que seus moradores não frequentem espaços coletivos. As casas são voltadas para dentro, sendo possível apenas visualizar do lado de fora dos muros águas furtadas dos telhados de suas casas. Deduz-se que elementos arquitetônicos sofisticados são utilizados para diferenciar os membros dessa comunidade de iguais, na medida em que seus moradores buscam se destacar dos demais.

A percepção da população adjacente sobre os enclaves é a de que são locais seguros e importantes porque proporcionam a seus moradores um espaço livre de violência e criminalidade, funcionando como um refúgio em meio ao 'caos urbano'. A sensação de exclusão parece pouco apurada. Por outro lado, há quem vincule a homogeneidade socioeconômica à monotonia. Além disso, associam-nos à perda de liberdade ocasionada pelo adensamento populacional e pelo sistema de vigilância integral. Por fim, foram levantadas questões relativas a alterações urbanísticas promovidas a partir da implantação desses condomínios: de maneira geral, a alteração mais significativa foi o adensamento populacional e, como consequência, o aumento no tráfego de veículos da região, especialmente nas vias arteriais.

\section{A Região Oeste como recorte territorial}

Para dimensionar os efeitos urbanísticos, sociais e ambientais causados pela implantação de condomínios fechados, procedeu-se a um recorte da região de estudo, que compreende os bairros Jardim Samambaia, Malota, Vila Alvorada, Casa Branca-Setor Industrial, Gramadão e Moisés (Figuras 5 e 6).

Figura 5 - Município de Jundiaí: o Recorte Territorial da Região Oeste e suas relações com a Cidade

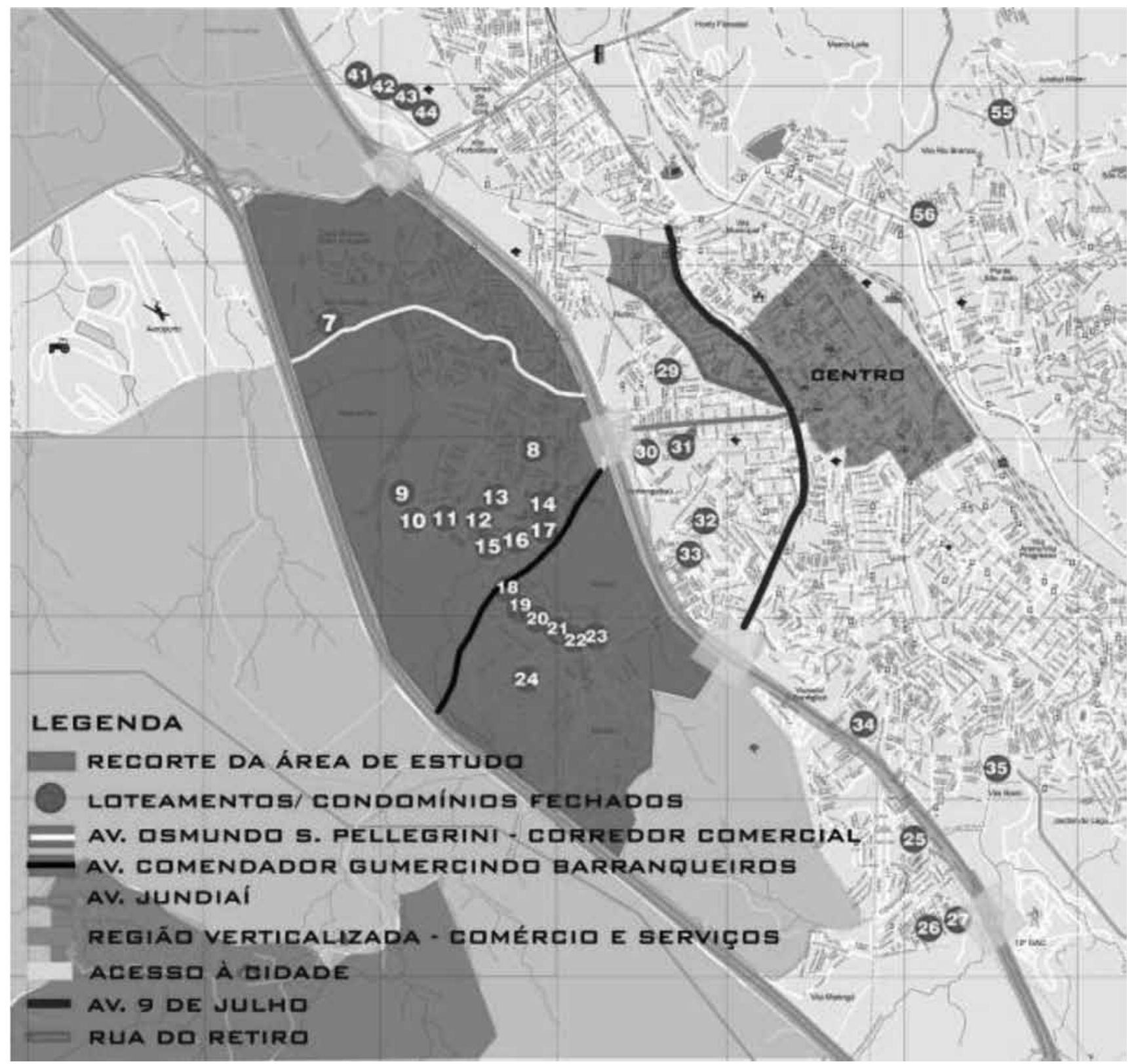


Figura 6 - Município de Jundiaí: Localização e Delimitação dos Condomínios e Loteamentos Fechados no Recorte Territorial da Região Oeste

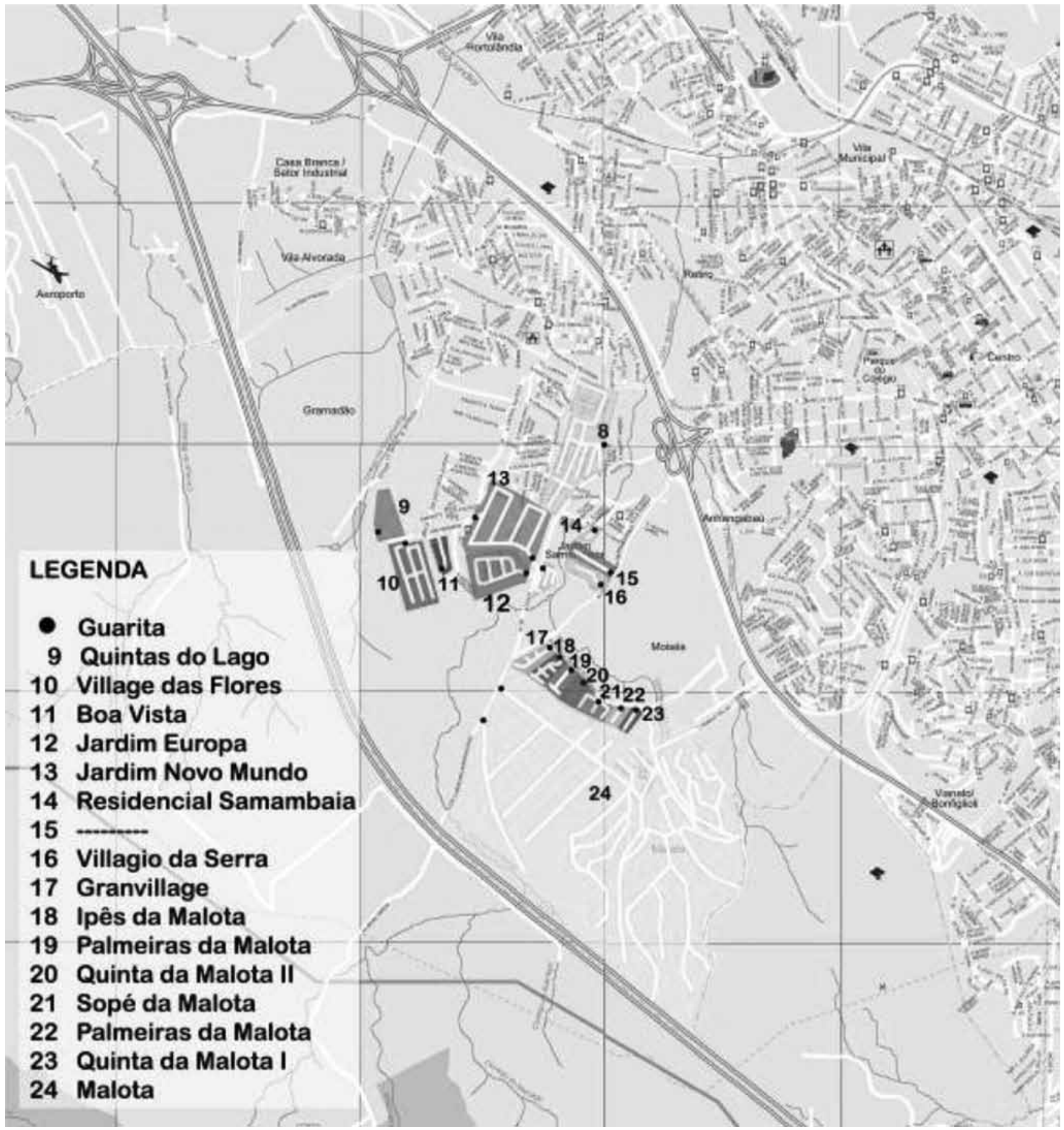

Tal opção metodológica se justifica por sua localização, entre as vias Anhanguera e Bandeirantes, além de situar-se nas imediações da Serra do Japi, declarada pela UNESCO "Reserva da Biosfera da Mata Atlântica", em 1992. Tal proximidade contribui para sua valorização, de sorte que nela identificam grande potencial para a instalação de empreendimentos caracterizados pelo isolamento da malha urbana por meio de barreiras físicas. Enfim, o recorte apresenta quantidade significativa de loteamentos e condomínios fechados, em sua maioria de alto padrão. A escolha também se justifica pelo fato de que alguns desses loteamentos foram os pioneiros a adotar a forma fechada.
O recorte territorial abrange a microbacia do Córrego do Moisés, composta pelo Córrego da Estiva, o qual nasce na Serra do Japi e é utilizado para o abastecimento da cidade. Esta microbacia é protegida pela Lei Municipal n. 2.405/1980, que disciplina o uso do solo para a proteção das coleções de água e demais recursos hídricos. Tal legislação foi aprimorada no Plano Diretor de 2004, que traz como objetivos a conservação da qualidade da água nas nascentes e nos respectivos cursos d'água, estimulando a preservação das matas existentes e a recomposição da vegetação ciliar removida. Estabelece, ainda, que em cada sub-bacia a ocupação não deve ultrapassar o valor de 
30hab/ha, salientando que novas ocupações devem comportar valor máximo de $16 \mathrm{hab} / \mathrm{ha}$. Excetuando-se lotes de uso residencial regularmente aprovados, com área inferior a $1.000 \mathrm{~m}^{2}$, em pelo menos $50 \%$ dos imóveis deve haver manutenção ou recomposição da mata nativa. Também preconiza a ocorrência de usos que mantenham a permeabilidade do solo e a produção de água em quantidade e qualidade.

A rodovia Anhanguera ainda é uma barreira de transposição e interligação entre a área de estudo e a cidade. Ocorre o truncamento do tecido urbano, pois a travessia do setor oeste para o centro da cidade é feita especialmente através do trevo da Avenida Jundiaí. Este constitui o principal acesso à cidade e, nos horários de pico, apresenta grande volume de tráfego e congestionamentos.

O recorte urbano abrange a Zona de Conservação Ambiental (ZC), Zonas Residenciais 1, 2 e 3, além da Zona Industrial. Na Zona Residencial 1 (ZR1), está o loteamento fechado Santa Tereza. A legislação de uso e ocupação do solo determina que nesta área a densidade máxima permitida seja de 80 hab/ha, e os lotes devem ter área mínima de $500 \mathrm{~m}^{2} \mathrm{e}$ testada de $12 \mathrm{~m}$. Os loteamentos fechados Quintas do Lago e Village das Flores encontram-se na Zona Residencial 2 (ZR2). Esta assume contornos mais permissivos quanto à sua ocupação, estabelecendo densidade máxima de 200 hab/ha, além de prever lotes com área mínima de $250 \mathrm{~m}^{2}$ e $10 \mathrm{~m}$ de testada.

Já os demais empreendimentos, representados pelos loteamentos fechados Malota, Jardim Europa, Jardim Novo Mundo, Samambaia, Sopé da Malota, Palmeiras da Malota II, Quinta da Malota I, além dos condomínios fechados Villagio da Serra, Granvillage, Ipês da Malota, Palmeiras da Malota I e Quinta da Malota II, encontram-se na Zona de Conservação (ZC). De acordo com o artigo $6^{\circ}$ da Lei Municipal n. 416/2004, esta "abrange áreas que em função do interesse de proteção dos atributos naturais, necessitam de critérios especiais de uso e ocupação do solo". Estabelece, ainda, que novos empreendimentos ou utilização de glebas com áreas superiores a $2.000 \mathrm{~m}^{2}$ deverão garantir áreas mínimas permeáveis de 30\% da área do imóvel (áreas verdes) quando se referir a loteamentos ou desmembramentos e, no caso de outras destinações, devem representar 50\% do imóvel (áreas verdes e de preservação permanente ou previstas no projeto).

A região escolhida abrange a bacia do Córrego do Moisés, manancial de classe II (Decreto n. 10.755/1977), ou seja, sua água destina-se ao abastecimento para consumo humano após tratamento simplificado convencional, importante forma de abastecimento a um manancial, especialmente nas estiagens. É preocupante, pois, a instalação de novos empreendimentos como condomínios e loteamentos fechados nessa região, em virtude do uso intensivo dos espaços, o que causa grande desgaste aos ecossistemas. Con- juntos residenciais promovem a impermeabilização de grandes áreas, além de desmatamento na implantação de edificações e equipamentos, e poluem o ambiente com dejetos gerados pela construção civil.

Spirn (1995) aborda o tema hídrico salientando que a pavimentação e redes de esgoto urbanas alteram a hidrologia da cidade, impactando diretamente a oferta da água e sua qualidade: implantações urbanas que acentuam a impermeabilização do solo interferem na absorção de água, reduzindo o volume de água dos rios e córregos. Águas pluviais são absorvidas pelo solo, constituindo a principal fonte de abastecimento dos mananciais e, como suas adjacências são impermeabilizadas, especialmente os topos de morro, reduz-se o volume de água dos cursos d'água, podendo até mesmo serem extintos e assim afetarem o abastecimento da cidade.

A conservação da vegetação nos topos de morro constitui elemento estratégico. É imprescindível manter sua permeabilidade, pois nestas áreas é absorvida grande parte do fluxo das chuvas, diminuindo o volume e a velocidade das águas num contexto em que a impermeabilização solo pode provocar verdadeiras enxurradas e inundações na medida em que a água não mais é absorvida no decorrer de seu trajeto de escoamento. A tendência é que "as cidades rapidamente se tornarão mais secas, mais quentes, menos atrativas, com enchentes mais devastadoras, mais erosão e pior qualidade de água" (SPIRN, 1995, p. 189). Como requer insumos básicos para sua consecução (recursos naturais, por exemplo), o adensamento tende a comprometer as condições ambientais, notadamente no que diz respeito aos recursos hídricos e à cobertura vegetal.

A DAE S.A. é a empresa responsável pelo saneamento do município, abrangendo captação, tratamento e distribuição de água, tratamento e reciclagem de lodo de esgoto. Em 2000, foi transformada em empresa de economia mista - arranjo institucional e modalidade de gestão que passa a incluir captação de recursos privados, de modo que a missão da empresa deixa de ser estritamente social para também incorporar objetivos de lucratividade. Jundiaí coleta aproximadamente 97\% de todo o esgoto gerado, tratando-o e reciclando-o.

Em 1993, o setor imobiliário se mobilizou para aprovar legislação que regulamentasse a implantação das vilas residenciais. Assim, a Prefeitura elaborou instrução na Secretaria de Obras para permitir a execução de mais de uma residência num mesmo terreno. Para tanto, exigia-se a apresentação de anteprojeto do parcelamento do solo, projeto das unidades residenciais e previsão do arruamento. Em 1996, são promulgadas a Lei n. 223 (regulamentando a implantação das Vilas Residenciais) e a Lei n. 221 (que dá diretrizes à instalação de condomínios fechados). Tal legislação foi o caminho através do qual loteamentos e condomínios fechados encontraram amparo para sua regulamentação urbanística. 
O Art. 40 da Lei Complementar n. 416/2004, que dispõe sobre o zoneamento da cidade, regulamenta as vilas residenciais, permitidas em lotes da zona urbana com área máxima de $10.000 \mathrm{~m}^{2}$. São conjuntos de residências unifamiliares que podem assumir a forma de edificações isoladas ou agrupadas. Estas devem estar voltadas para as vias ou áreas internas, sem acesso independente para a via pública. A edificação deve ter gabarito máximo de dois pavimentos, excluído o da garagem. Precisam apresentar recuo frontal de $5 \mathrm{~m}$ em relação ao alinhamento, as vias internas para circulação de veículos devem apresentar declividade longitudinal máxima de $20 \%$ e largura mínima de $6 \mathrm{~m}$, ao passo q ue as vias internas para circulação de pedestres devem ter declividade longitudinal máxima de 15\% ou esta deve ser executada em escadaria. A região de estudo compreende a Zona de Conservação, a qual estabelece que os lotes devem ter frente mínima de $25 \mathrm{~m}$, além de estabelecer que cada unidade habitacional deva ter área mínima de $600 \mathrm{~m}^{2}$.

A legislação de vilas residenciais foi utilizada para a implantação dos seguintes loteamentos fechados: Quinta da Malota I, Palmeiras da Malota I e II, Ipês da Malota, entre outros. Já a figura dos conjuntos habitacionais, que representam os condomínios fechados, foi utilizada para aprovação do Quinta da Malota II.

O Plano Diretor (Lei Municipal n. 415/2004) trata apenas do fechamento dos loteamentos, os quais podem adotar a forma fechada desde que não contenham áreas públicas dentro de seu perímetro interno, não prejudiquem a continuidade da malha viária, além de não conterem vias estruturais (Art. 78). O poder público concederá o uso do sistema viário e, se for de seu interesse, o loteamento deverá voltar a adotar a forma aberta. A iniciativa privada assume a iluminação e pavimentação das vias de veículos e pedestres, e deverá se responsabilizar por levar as redes de água potável e pluvial, e de esgotos. Na prática, a Lei de Vilas se tornou um instrumento de adensamento para os empreendedores imobiliários. $\mathrm{O}$ instrumento de Vilas Residenciais foi implantado como releitura do desenvolvimento industrial da cidade de Jundiaí: o planejamento do município considerou importante preservar a figura histórica das vilas que outrora tinham como principal demanda o operariado industrial e trabalhadores ferroviários.

Quanto à mobilidade, a relação desta região com a malha urbana encontra-se truncada porque o tecido urbano é cortado pelas rodovias Anhanguera e Bandeirantes. Assim, é imperativo o investimento do poder público em soluções que visem à transposição entre o centro da cidade e o vetor oeste. Também se faz inadiável a ampliação do transporte público coletivo para atender a população dos estratos inferiores, além da implantação de passarelas. Trata-se, enfim, de melhorar a acessibilidade e a mobilidade urbana. A área já apresenta exemplo de fragmentação viária proporcio- nado pela implantação de condomínios ou loteamentos fechados: o loteamento Santa Tereza (originalmente aberto) passou a ser loteamento fechado e suas vias, que conectavam os bairros Jardim Samambaia e vila Alvorada, foram obstruídas com a construção de muros. Consequências: fragmentação da malha viária e aumento das distâncias.

O recorte vem se mostrando um importante ímã para investimentos, pois seus moradores possuem alto poder aquisitivo, além de contar com infraestrutura urbana completa e localização privilegiada. A atratividade pode ser exemplificada pelo grupo Iguatemi, que projeta implantação de um Shopping Center com área total de $225 \mathrm{mil} \mathrm{m}^{2}$, sendo 103,5 mil m² de construção. O público-alvo deste empreendimento é constituído das classes A e B e sua implantação, prevista para 2011, deve trazer sérios impactos para a região, como na dinâmica da produção do espaço urbano, malha e tráfego viários. Para evitar futuros transtornos, seria imprescindível que a administração pública fizesse exigências à iniciativa privada, especialmente no sistema viário, como o alargamento das marginais da rodovia Anhanguera e mais opções de transposição desta, tanto para veículos como para pedestres.

É indispensável, pois, a ação do poder público para evitar que loteamentos irregulares se disseminem em áreas com atributos naturais, por meio de mecanismos legais, tais como a implantação das Zonas Especiais de Interesse Social (ZEIS) - frações do território destinadas à promoção de políticas habitacionais de interesse social e regularização fundiária. Previstas no Plano Diretor, as ZEIS permitiriam a permanência das classes mais baixas, através de uma ocupação racional do território mediante critérios urbanísticos específicos que observem suas limitações tendo em vista sua localização em área de proteção ambiental.

Sejam quais forem os instrumentos utilizados, a legislação urbanística precisa se equipar e se atualizar para enfrentar as tendências contemporâneas e assegurar a função social da cidade, como assevera o Estatuto da Cidade (Lei Federal n. 10.257, de 10 de julho de 2001), que nada mais é do que a regulamentação dos capítulos 182 e 183 da Constituição Federal.

\section{Conclusões}

Enclaves fortificados representam um novo padrão de segregação, interferindo profundamente na sociabilidade urbana, afora seus agudos impactos ambientais. Isto ocorre porque os espaços públicos são relegados pelas elites, que se fecham em busca de segurança e assim negam a experiência da vida pública da cidade, marcada pela diversidade e imprevisibilidade. O presente estudo empírico revela que estes 
moradores carecem de relações com a cidade e com a população vizinha.

Do ponto de vista da sociabilidade, a propagação desse modelo residencial constitui uma tendência de expansão urbana que atende unicamente às demandas das classes mais abastadas. A sensação de segurança é proporcionada pelos equipamentos de vigilância exemplificados por muros, cercas elétricas, sistemas de câmeras e guardas armados que circulam no interior dos condomínios. Mais: tal figura urbanística alavanca o mercado imobiliário e o setor da construção civil, que têm nos condomínios fechados empreendimentos lucrativos utilizando-se de propagandas persuasivas que vendem 'lugares ideais' para residir com conforto, segurança e tranquilidade - fatores decisivos no imaginário da almejada qualidade de vida.

A segurança é o principal motivo para residir nesses conjuntos residenciais. E também se pode destacar a busca por status social (não explicitado nas entrevistas), visto que este constitui uma marca de distinção e neles também se partilham valores. Em outras palavras, seus moradores procuram viver numa comunidade de iguais, onde todos são do mesmo estrato social e possuem concepções de mundo semelhantes.

No plano urbanístico, há exemplos de interrupções da malha viária resultantes da implantação dos enclaves. Vias públicas deixam de ser instrumento de conexão entre os bairros, cujas obstruções como muros atuam como barreira física entre o condomínio e demais áreas da cidade. Isto contribui para criar uma cidade desconexa, agravando os problemas de fluxo viário ao aumentar as distâncias a serem percorridas. Assim, sobrecarregam as vias principais, que passam a ser as únicas para o deslocamento na medida em que vias locais - agora cercadas e pertencentes aos condomínios e loteamentos fechados - são destinadas ao uso privado da população local.

Em Jundiaí, verifica-se uma tendência de expansão desses empreendimentos em direção ao entorno da Serra do Japi e à zona rural da cidade, regiões que possuem atributos ambientais potencialmente atrativos para possibilitar a instalação de condomínios fechados. Desse modo, a iniciativa privada opera um movimento junto ao poder público municipal para que critérios de uso e ocupação sejam flexibilizados de modo a permitir a implantação de empreendimentos de alto e médio padrão caracterizados como enclaves fortificados. Mas vale lembrar: são áreas ambientalmente frágeis. Instrumentos da legislação são distorcidos para promoverem o adensamento da ocupação populacional, podendo ocasionar danos ambientais ao possibilitarem o desmatamento de áreas verdes, assim como a impermeabilização de extensas áreas, tendo como consequência a diminuição da absorção de águas pluviais pelo solo, alterando assim a disponibilidade de recursos hídricos que marca o abastecimento da cidade. Nesses termos, os dilemas ambientais e de integração e melhoria da infraestrutura de Jundiá ganham nova escala e complexidade.

Paradoxalmente, os enclaves também atraem a população pobre, que, para evitar deslocamentos, se instala em áreas adjacentes. Essa demanda populacional - prestadora de serviços aos condomínios em funções como limpeza, segurança, jardinagem etc. se dirige a áreas ambientalmente frágeis. Em cidades fragmentadas e cada vez mais divididas socialmente, a cidadania vai perdendo significado, afinal, também os direitos sofrem uma hierarquização socioespacial. Jundiaí, portanto, reproduz similaridades em relação às motivações (segurança) e aos impactos produzidos pela generalização dos enclaves (segregação e fragmentação), ao mesmo tempo em que revela particularidades, como sua escala, distribuição espacial, instrumentos urbanísticos institucionais e implicações na integração do espaço urbano.

Diferentemente do que se poderia supor, a proliferação desses enclaves deixou de ser privilégio das grandes cidades. O exemplo empírico de Jundiaí - estimulado pela permissividade da legislação urbanística e pela leniência das autoridades públicas, além da motivação do refúgio contra a violência urbana - revela um fenômeno que se generaliza em cidades médias. No caso em questão, as vantagens logísticas do município - proximidade da capital e de Campinas e acesso a uma privilegiada rede viária - também potencializam sua atratividade, não sem graves impactos. 


\title{
Referências
}

BARCELLOS, T. M de; MAMMARELLA, R. O significado dos condomínios fechados no processo de segregação espacial nas metrópoles. Porto Alegre: Secretaria do Planejamento e Gestão/ Fundação de Economia Estatística, 2007.

CALDEIRA, T. P. Cidade de muros: crime, segregação e cidadania em São Paulo. São Paulo: Ed. 34, 2000.

CANO, W. Raízes da concentração industrial em São Paulo. Rio de Janeiro: Difel, 1977.

D’OTtAVIANO, M.C.L. Condomínios fechados na região metropolitana de São Paulo: fim do modelo rico versus periferia pobre. Tese (Doutorado em Urbanismo) - Faculdade de Arquitetura e Urbanismo da Universidade de São Paulo, 2008.

FERREIRA. F. B. Transformações urbanas na cidade de São Carlos: condomínios residenciais fechados e novas formas de sociabilidade. In: XV ENCONTRO NACIONAL DA ABEP, Caxambu, 18-22 set. 2006.

JANOSCHKA, M.; BORSDORF, A. Condomínios fechados and barrios privados: the rise of private residential neighborhoods in Latin América. In: Glasze, G.; WEBSTER, C.; FRANTZ, K. (Ed.). Private Neighborhoods: global and local perspectives. London: Routledge, in press, 2004.

MIGLIORANZA, E. Condomínios fechados: localizações da pendularidade - um estudo de caso no município de Valinhos, SP. Dissertação (Mestrado em Ciências Sociais) Instituto de Filosofia e Ciências Humanas da Universidade Estadual de Campinas, 2005

NEGRI, B. As políticas de descentralização industrial e o processo de interiorização em São Paulo: 1970-1985. In: TARTAGLIA, J. C.; OLIVEIRA, O.L. (orgs.). Modernização e desenvolvimento do interior de São Paulo. São Paulo: Edunesp, 1988.

ROITMAN, S. Urbanizaciones cerradas: estado de la cuestión hoy y propuesta teórica. Revista de Geografia, Norte Grande, Santiago, n. 32, 2004.

SPINELLI, V. Bauman e a impossibilidade da comunidade. CAOS - Revista Eletrônica de Ciências Sociais, n. 11, p. 01-13, 2006. Disponível em: <http://www.cchla.ufpb.br/ caos/n11/01.pdf>. Acesso em: 20 set. 2008.

SPIRN, A.W. O jardim de granito: a natureza no desenho da cidade. São Paulo: Edusp, 1995.

\section{Fortified enclaves and urban segregation: the case of Jundiai}

\begin{abstract}
The article discusses the spread of closed condominiums in Jundiaí (SP). The studies about this phenomenon have predominantly focused on metropolitan areas; therefore, the relevance of research on medium-sized cities in order to identify similarities and differences among different urban scales. The main objective was to investigate the spacing phenomenon of closed condominiums as a housing pattern tendency as well as its social, urban and environmental impact. This study encloses the period from 1970 to the present.
\end{abstract}

Keywords: fortified enclaves; urban segregation; Jundiaí.

\section{Enclaves fortificados y segregación urbana: el caso de Jundiaí}

\section{resumen}

El artículo examina la proliferación de barrios cerrados en la ciudad de Jundiaí (SP). Los estudios acerca de este fenómeno han sido concentrados principalmente en las áreas metropolitanas, por ello la relevancia de la investigación sobre las ciudades medianas a fin de identificar las similitudes y diferencias entre las distintas escalas urbanas. El principal objetivo fue investigar el fenómeno de las comunidades cerradas en el espacio como la tendencia de la vivienda, así como sus impactos sociales, urbanos y medioambientales. Por lo tanto se adopta el alcance cronológico como periodo transcurrido desde la década de 1970 hasta la actualidad.

Palabras claves: enclaves fortificados; segregación urbana; Jundiaí. 